\title{
BMJ Open Quality Improving interventions for parents of children and young people with autism spectrum disorder (ASD) in CAMHS
}

\author{
Laura Ann Roughan, Jenny Ruth Parker, Louise Mercer
}

To cite: Roughan LA, Parker JR, Mercer L. Improving interventions for parents of children and young people with autism spectrum disorder (ASD) in CAMHS. BMJ Open Quality 2019;8:e000261. doi:10.1136/ bmjoq-2017-000261

- Additional material is published online only. To view please visit the journal online (http://dx.doi.org/10.1136/ bmjoq-2017-000261)

Received 21 November 2017 Revised 21 September 2018 Accepted 20 March 2019

\section{Check for updates}

(c) Author(s) (or their employer(s)) 2019. Re-use permitted under CC BY-NC. No commercial re-use. See rights and permissions. Published by BMJ.

City and Hackney CAMHS, East London NHS Foundation Trust, London, UK

Correspondence to Dr Laura Ann Roughan; I.roughan@nhs.net

\section{ABSTRACT}

With ever increasing recognition and diagnosis of autism spectrum disorders (ASD) in children within mainstream schooling, there was a need for City and Hackney Child and Adolescent Mental Health Services to develop innovative interventions to meet the needs of a large client group, with limited clinician resource. The importance of psychoeducation about ASD for parents of children recently diagnosed is understood; however, feedback from our service users highlighted the additional need for ongoing access to a network of professional support. Using quality improvement (QI) methodology, we aimed to develop a sustainable regular group programme that was relevant for parents. The total number of parents attending each monthly group over a specific period of time was tracked (from February 2015 to May 2017). A service user questionnaire was devised to gain feedback from each group on parental confidence in managing a child with ASD and their satisfaction. These were given to parents at the end of each group. The Plan Do Study Act cycles were applied and evaluated in the Ql framework to assess the impact of the following change ideas: letter reminders, a focus group, an email information and reminder system, and a parent co-lead group. Overall, attendance at the monthly groups increased and remained stable. Satisfaction with the groups was high (eg, $91 \%$ of the attendees were either 'Quite Satisfied' or 'Extremely Satisfied'). Of those attending, 82\% reported increases in their own confidence in managing their child with ASD. The QI approach allowed us to systematically develop efficient systems and cost-effective ways to run interventions within our ASD pathway. Parents reported high levels of satisfaction with the groups and increased confidence in their ability to parent their child with ASD.

\section{PROBLEM}

Research highlights the importance of psychoeducation about autism spectrum disorder (ASD) for parents of recently diagnosed children. ${ }^{12}$ Groups such as Early Bird and Early Bird Plus ${ }^{34}$ are available in the borough from other services, but have waiting lists of over 1 year. This was reflected in the referrals to City and Hackney Child and Adolescent Mental Health Services (CAMHS) for crisis management of school refusal, challenging behaviours and managing exclusions. Many families had not accessed information about ASD, did not understand the condition and had low confidence in their ability to manage the difficulties presented. With recognition that ASD is a lifelong condition, interventions are needed to be able to support these families who may experience difficulties at different transition points in their child's development.

City and Hackney CAMHS is a community-based service within London providing mental health services for young people 0-18 years. The Autism Pathway provides assessment and a range of interventions for young people with ASD and their families. Our community is socioeconomically and ethnically diverse. Our young people attend mainstream and specialist schools locally and in neighbouring boroughs. This is a busy service with limited capacity to meet growing demand from families and schools.

In the 12 months since March 2016, there were 238 referrals for ASD assessments (ages 5-18 without learning disability). In addition, the Autism Pathway typically has a case load of approximately 60 children and young people who are in need of a specific intervention for a coexisting mental health conditions (eg, anxiety disorders/depression/attention deficit hyperactivity disorder). Clinician resources are limited with one consultant child and adolescent psychiatrist (4 sessions), one clinical psychologist (10 sessions) and some additional sessions from clinicians in different pathways for assessments. It was important that the pathway was able to develop innovative interventions to meet the needs of a large client group, with limited clinical resource.

A two-session psychoeducation group ('ASD Psycho-education Group') was devised for parents to increase their understanding of ASD, support parents to talk about their feelings surrounding the diagnosis and help them to develop some practical strategies to manage their child with ASD. Feedback from these groups was generally positive and highlighted that meeting other parents of children and young people with ASD was 
also very helpful. However, despite this providing the recommended follow-up to a specialist assessment, ${ }^{5}$ many parents reported the need for further advice and support to manage their child with autism, including ongoing access to support from a range of professionals (eg, occupational therapy $[\mathrm{OT}]$, speech and language therapy [SLT], psychology).

We also noted that many families were being referred to multiple services at the same time (CAMHS, OT, SLT) with some duplication of input. In collaboration with colleagues from OT and SLT, we developed groups covering different topics relevant to ASD (eg, managing challenging behaviour, developing social skills, how to talk about ASD) and teaching parents ASD-specific strategies: 'Parent ASD Groups'. The aim was to help parents feel more able to cope with their child's ASD. It was essential that there was a system in place to ensure that as many parents as possible were making use of the groups. It was also important that the groups were relevant and helpful to parents. Based on a previous experience of running a yearly ASD workshop, it was agreed that attendance of approximately 15-20 parents was manageable for facilitators, allowing space for questions, breaking out into small group work and making use of the room capacity.

The aim of the quality improvement (QI) project was therefore to ensure the ASD pathway maximised its limited resources by providing an ASD parent group intervention that was relevant for families, as measured by the following:

1. Increasing the total number of parents attending regular drop-in 'Parent ASD Groups' to 15-20 parents attending each group.

2. Parents reporting an increase in their own perceived confidence in their ability to manage their child's ASD following attendance at a group.

3. Parent-reported satisfaction in the intervention being offered.

\section{BACKGROUND}

ASD forms a significant proportion of the work within a CAMHS. At least 1 in 10 children with ASD will access CAMHS for further intervention for a coexisting mental health condition. ${ }^{6}$

Guidelines for the management and support for children with $\mathrm{ASD}^{57}$ provide some guidance on what services CAMHS should be offering. However many CAMHS have limited resources and there is less on offer to families beyond psychoeducation and signposting around the condition.

ASD is a lifelong developmental condition; children, young people and their parents typically need varying levels of professional support at different points in their development. Research has found prevalence rates of $70 \%$ of young people with ASD with at least one coexisting disorder and $41 \%$ with two or more. ${ }^{8}$ This may require additional CAMHS interventions such as structured individual therapy (eg, modified cognitive-behavioural therapy) or medication; however, this level of intervention is not always warranted. In many cases where CAMHS thresholds are not met, there is often a lack of appropriate service provision or expertise, and families are left to wait for problems to escalate. ${ }^{9}$

Research has found that parenting groups devised for typically developing children can be modified to incorporate our existing knowledge about ASD-specific strategies in the home and other settings (eg, predictability, routine, use of visual strategies, social skills teaching). ${ }^{10}$ These modifications have resulted in effective parenting groups specifically aimed at managing children with ASD. ${ }^{11}$ There is also evidence that teaching parents how to modify the environment around their child and implement ASD-specific strategies to manage behaviour in children with ASD can have a positive impact on the child's emotion regulation and anxiety. ${ }^{12}$ Furthermore, ASD-focused parenting interventions have been found to reduce aggressive behavioural problems in children with $\mathrm{ASD},{ }^{13}$ and in the long term prevent children with ASD from developing further mental health issues.

Research into group work suggests a number of additional benefits, such as meeting other parents in a similar position and seeking support and advice from a parent who has the same issues. In addition, there is evidence to suggest increased parental self-efficacy ${ }^{14}$ and increased parenting satisfaction ${ }^{11}$ in this client group. From a service perspective, groups are a cost-effective way of delivering professional-led interventions to a large cohort of families.

Many parenting programmes aimed at this client group are closed groups and run for a limited number of sessions (eg, 12 sessions). There is little research into groups which provide ongoing 'drop-in' groups as a way of supporting parents of children with ASD. This QI project aims to provide some evidence that this model of working is a useful way for services to manage growing case loads of children and young people with ASD, who may otherwise not get a service (eg, without a severe coexisting mental health condition).

\section{MEASUREMENT}

Data collection began in February 2015. Primary measures included collecting data on the number of parents attending each 'Parent ASD Group'; getting feedback from parents on the impact on their confidence in their ability to manage their child; and parent satisfaction following the group. With the advertisement and introduction of the group, there was an initial reasonable attendance of 13 parents. However, in the following months, this dropped to 7 and 9 parents, highlighting the need to understand and address the low uptake of the group intervention. The number of parents attending each group was recorded during a specific period of time (from February 2015 to May 2017), with the aim of increasing attendance to 15-20 parents per group (to maximise the capacity of the resources). 


\section{ASD Parent Groups Evaluation Form}

Name Child's name

Please underline or circle the most appropriate response for you.

1. How helpful has it been to come to the groups for parents of children and young people with ASD? \begin{tabular}{|l|l|l|l|l|}
\hline not at all helpful & not very helpful & a bit helpful & quite helpful & extremely helpful \\
\hline
\end{tabular}

2. How enjoyable has it been to come to the group?

\begin{tabular}{|l|l|l|l|l|}
\hline not at all enjoyable & not very enjoyable & a bit enjoyable & quite enjoyable & $\begin{array}{l}\text { extremely } \\
\text { enjoyable }\end{array}$ \\
\hline
\end{tabular}

3. How much more do you know about ASD as a result of coming to the group?

\begin{tabular}{|c|c|c|c|c|}
\hline $\begin{array}{c}\text { no more than } \\
\text { before }\end{array}$ & not much more & a bit more & a fair bit more & lots more \\
\hline
\end{tabular}

4. How much more do you understand about your child as a result of coming to the group?

\begin{tabular}{|c|c|c|c|c|}
\hline $\begin{array}{c}\text { no more than } \\
\text { before }\end{array}$ & not much more & a bit more & a fair bit more & lots more \\
\hline
\end{tabular}

5. Do you feel more confident as a parent as a result of coming to the group?

\begin{tabular}{|c|c|c|c|c|}
\hline $\begin{array}{c}\text { no, I do not feel } \\
\text { any more } \\
\text { confident }\end{array}$ & $\begin{array}{c}\text { I feel perhaps a } \\
\text { little bit more } \\
\text { confident now }\end{array}$ & $\begin{array}{c}\text { I definitely feel a } \\
\text { bit more confident } \\
\text { now }\end{array}$ & $\begin{array}{c}\text { I feel quite a lot } \\
\text { more confident } \\
\text { now }\end{array}$ & $\begin{array}{c}\text { Ifeel very much } \\
\text { more confident } \\
\text { now }\end{array}$ \\
\hline
\end{tabular}

6. Do you feel less "alone" or isolated as a result of coming to the group?

\begin{tabular}{|c|c|c|c|c|}
\hline $\begin{array}{c}\text { no, I do not feel } \\
\text { any less alone }\end{array}$ & $\begin{array}{c}\text { I feel perhaps a } \\
\text { little less alone } \\
\text { now }\end{array}$ & $\begin{array}{c}\text { I definitely feel a } \\
\text { bit less alone }\end{array}$ & $\begin{array}{c}\text { I feel quite a lot } \\
\text { less isolated now }\end{array}$ & $\begin{array}{c}\text { I feel very much } \\
\text { less isolated now }\end{array}$ \\
\hline
\end{tabular}

7. Overall, how satisfied do you feel with the group?

\begin{tabular}{|l|l|l|l|l|}
\hline not at all satisfied & not very satisfied & a bit satisfied & quite satisfied & extremely satisfied \\
\hline
\end{tabular}

8. Do you have any comments/suggestions for future sessions?

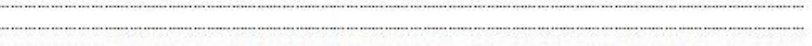

Thank you!

Figure 1 Copy of the parent questionnaire used to evaluate the groups. ASD, autism spectrum disorder.

Other primary measures included collecting quantitative and qualitative analyses of responses to a questionnaire given to parents at the end of each group (see figure 1 for a copy of the questionnaire). A total of 20 groups have been run since the start of the QI project in February 2015. Of these, 190 questionnaires were completed out of a total of 295 attendees, a response rate of $64.4 \%$ of parents providing feedback.

Throughout the project, a number of Plan Do Study Act (PDSA) cycles were applied and evaluated using QI methodology with the aims to increase attendance and for parents to give positive feedback on their confidence in managing their child's ASD following attendance at a group, as well as satisfaction with the group.

\section{DESIGN}

There was a clear need to have an intervention offer in place that could appropriately meet the demands of a large cohort of families, and to do this with the limited resources available. The 'Parent ASD Group' aimed to address some of the needs of parents of children with ASD by offering a regular drop-in groups to support parents through key issues and times of transition for children and young people with ASD.
Staffing of the ASD pathway is limited (one clinical psychologist and one psychiatrist), and therefore the QI project team was small, formed of these two staff members. Regular monthly QI meetings were held to discuss progress, identify change ideas and plan PDSA. Due to the close working of the team, multiple conversations took place outside of formal QI meetings, which helped to generate more change ideas. The QI project started in June 2015 following QI training of staff within the ASD pathway. The groups were continually evaluated across a period of 2 years (until June 2017), when the project was completed.

The groups were formed by drawing on resources from other local services (eg, OT, SLT, educational psychology) outside of CAMHS. From the start of 2016 (following an initial planning and pilot phase), the groups ran on a regular basis, although PDSA cycles were carried out with less regularity due to resource and time constraints. It was important to involve parents via a focus group in the planning of the groups to ensure it was relevant and to increase motivation to attend. These families are often busy, and therefore an accessible reminder system was needed to ensure attendance to the groups. The group programme was set for a regular date/time, and this alongside the email system and collection of email consent from newly diagnosed families at feedback appointments meant the amount of resources required to 'invite' parents to the groups was low and easy to maintain.

This was an independent measures design as parents did not necessarily attend all of the groups due to the drop-in nature. Parents reported increased confidence in managing ASD, and satisfaction was measured independently of each group.

\section{STRATEGY}

Our primary aim was to increase attendance at the 'Parent ASD Group' to 15-20 parents each group. Quantitative and qualitative evaluation was used to determine how much each group helped parents feel more confident in their ability to manage their child's ASD, as well as how satisfied parents feel about each group. This involved parent feedback following attendance at groups, in addition to a focus group. Please see figure 2 for a visual representation of the study driver diagram.

\section{PDSA cycle 1}

At baseline, a 'Parent ASD Group' programme flyer with details for the next 6 monthly groups was produced and sent to parents by post. However, the number of parents attending decreased from 13 attending in group 1 to only 7 parents the following month, and 9 parents in the third group. The main aim was to increase attendance in the group. The first PDSA change idea was tested: readvertise each 'Parent ASD Group' to remind parents of the intervention on offer. In August 2015, 50 letters highlighting the date and time of the next group and selling the topic to parents were sent out to families. This dramatically 


\section{Improve ASD Interventions in CAMHS}

AIM

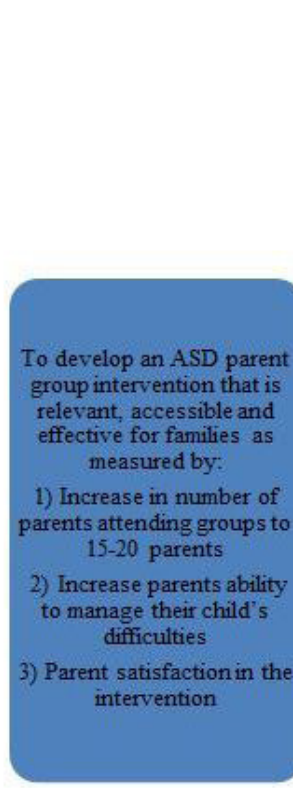

PRIMARY DRIVERS

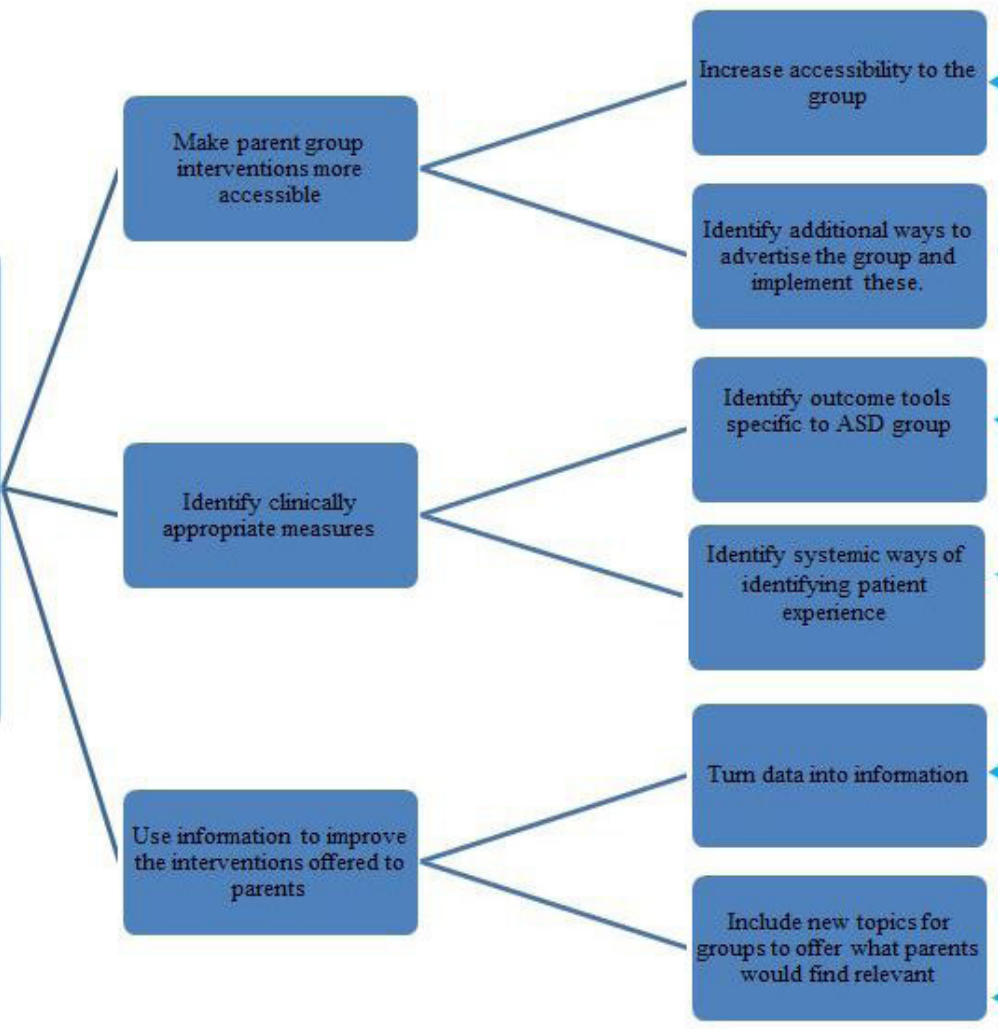

CHANGE IDEAS

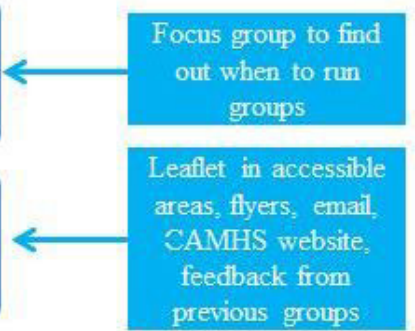

Research appropriate

ivols and discuss

with team / S Users

\section{Routinely collect}

measures in group to ensure its completed

Collate measures following each group

Ask parents for

feedback and discuss

with team re: clinical

appropriateness

Drop in groups for

crisis management

Figure 2 The driver diagram used as a study protocol. ASD, autism spectrum disorder; CAMHS, child and adolescent mental health service.

boosted the number to 19 ; however, this quickly fell again to 7 by November 2015 .

\section{PDSA cycle 2}

In December 2015, the second PDSA was aimed at reviewing the relevance of the groups for parents with the view to increasing attendance. A second change idea was tested: run a focus group with parents within the ASD pathway to plan the future group programme. Ideas from parents included a regular slot (easier to remember, plan in advance); discussion around key topics relevant to parents' needs; and the usefulness of handouts / resources, even if parents were unable to attend a group. This change idea resulted in useful qualitative data regarding what parents wanted from the groups (see figure 3 outlining some of the parents comments and suggestions). We learnt how to make the groups more appealing for parents and implemented a programme that included topic ideas from parents. This was helpful as a way of involving parents and making sure the groups were relevant to the parents' needs. Feedback helped inform the group programme and continues to be important in the running of each group. However, this did not have a significant impact on the number of parents attending the groups.

\section{PDSA cycle 3}

The use of postal letters to advertise groups was not a sustainable method due to the time taken to complete and reliance on the clinical team to enact each month, with low turnout to groups if omitted. Our third change idea was to introduce an email-based reminder system as a more efficient way to communicate for staff and potentially

\begin{tabular}{|l|}
\hline Comments from Parents \\
\hline More on sensory issues, building social stories, developing emotional toolkits \\
\hline A group topic on sensory issues and how they impact on behaviour \\
\hline It was really helpful to meet other parents and hear from them \\
\hline $\begin{array}{l}\text { I think the groups could be more practically useful if there was more use of actual examples } \\
\text { and case studies }\end{array}$ \\
\hline A group focusing on school and ASD \\
\hline Help on managing anxiety in my child \\
\hline Help with understanding the school system and EHCP process \\
\hline Regular groups at the same time so I know they are there to attend \\
\hline To run the same topics more than once as a refresher \\
\hline
\end{tabular}

Figure 3 A table to show examples of the feedback families gave regarding the groups (collected during the focus group and as part of service user questionnaires). ASD, autism spectrum disorder; ECHP, education health Care plan. 
more convenient for families. An email address was set up for the sole purpose of sending out details and reminders for the 'Parent ASD Group'. For safety, any communication sent by a parent to the inbox would receive an automatic reply stating that the inbox was unmonitored and provided details of how to contact the clinic. A system was devised to routinely collect consent for us to retain and used email addresses for the purpose of advertising groups only at ASD assessment (May 2016). Names were then added to a database and monthly reminders and handouts sent via email to parents on the database. This had an immediate positive impact, with increased attendance at the next 3 months of groups. This was found to be a quick and effective way of communicating with parents.

\section{PDSA cycle 4}

To make the groups more relevant, a PDSA was developed to include a parent in running a group. The parent-led group was well attended. There has not been a parent-service user leading all groups; however, guest speakers have been involved (at a request from parents) to support understanding on particular topics (eg, supporting ASD in school) and to support parents in finding the right services for their child (eg, voluntary sector services, online supplementary file 1 ).

\section{RESULTS}

The run chart (figure 4) visually displays data over time on the number of parents attending each 'Parent ASD Group'. The first significant shift in the data (more than four data points) is seen in October 2016. This shift shows the importance of the email reminders (PDSA 3) in supporting parents in attending the group. As more parents received the emails from the groups, consistency in the number of parents attending the group increases and then stabilises.

Over the course of the project, the average number of parents attending the 'Parent ASD Group' increased by approximately $100 \%$, from an average of 9 parents attending the first three groups at baseline to an average

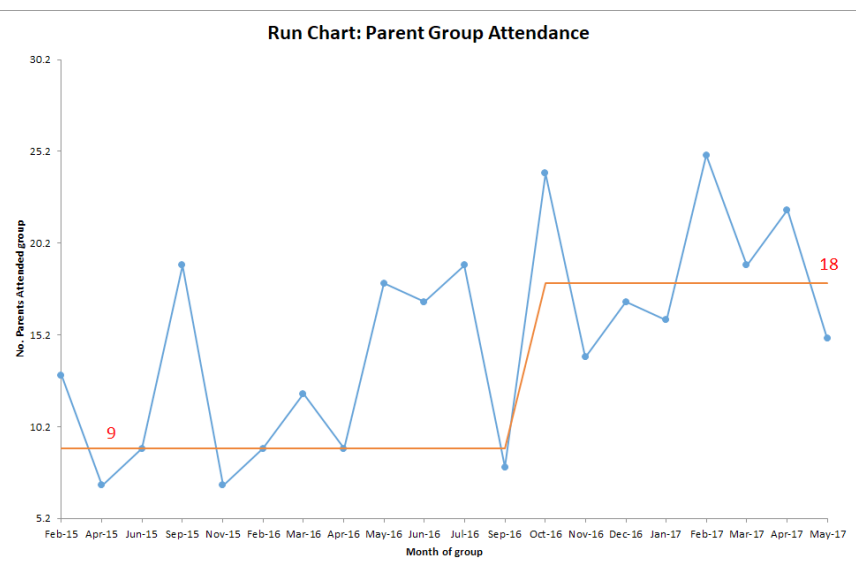

Figure 4 Run chart displaying data over time on the number of parents attending each 'parent ASD group'. ASD, autism spectrum disorder. of 18 parents attending the last eight groups, as displayed in the run chart (meeting our target of 15-20 parents per group). One problem identified was the reliance on a single clinician to remember to send the emails to parents. Quantitative and qualitative responses from the service user questionnaire were analysed (64.5\% response rate). Quantitatively, $91 \%$ of the attendees were either 'Quite Satisfied' or 'Extremely Satisfied' with the groups. The majority, 91\%, felt they had more knowledge about their child's ASD, and $81 \%$ of parents reported increase in self-confidence in managing their child with ASD following attendance at a group. Qualitative reports suggested a reduction in social isolation for parents (eg, 'I found it extremely useful to share/hear from other parents'). There was also positive feedback about the group's content (eg, 'Well-balanced by facilitators to include individual needs/stories and professional teaching to fit all').

\section{LESSONS AND LIMITATIONS}

The groups have been a positive way of offering a service to a large number of parents of children with ASD in the context of limited resources. The groups offer parents a multiagency approach to understanding and managing their child with ASD (eg, psychology/OT). Parent feedback suggests parents learn about ASD and how to support their child with communication and social interaction, as well as develop strategies to manage their child's emotions and sensory needs. QI methodology has assisted in identifying the problems (eg, sustaining repeated advertising of the groups) and identifying solutions (eg, email communication system) that are cost-effective.

There were some important observations made from the study that have not been captured in the data collection. New referrals into CAMHS for clients with an existing ASD diagnosis are being directed to the groups as the initial intervention offered within the service. For many, this is enough to address their needs. The family is then reviewed and closed (with the option to attend drop-in groups in the future if they would like to). In future, it would be useful to further explore the impact of attending groups on measures of behavioural difficulties and mental health in children and parents using a repeated measures study design with validated tools such as the Strengths and Difficulties Questionnaire.

For some families, the groups provide a containing intervention while they wait for a more intensive service. In addition, many existing clients have since been closed to the service but continue to access the groups intermittently as and when their needs change. We are observing the groups to be a helpful way to manage the flow in and out of CAMHS, with the groups providing support that is enabling families to manage themselves without continuous individual CAMHS interventions. These are important outcomes for how specialist services are run.

There were a number of limitations identified during the running of the QI project. The email reminder system continues to be reliant on one clinician to organise and 
send the reminders. There have been occasions during the project when this has not happened, and it was useful to note the direct negative impact this had on group attendance. In addition, we have identified some difficulties with recording the amount of clinical activity and client contacts, which requires more investigation as to how this issue can be resolved.

\section{CONCLUSIONS}

This QI project was motivated by a need to provide a relevant and effective service for families of children diagnosed with ASD who may not ordinarily have regular access to the expertise of experienced staff trained in ASD. There is literature that suggests teaching parents how to modify the environment around their child and implement ASD-specific strategies to manage behaviour in children with ASD can have a positive impact on the child's emotion regulation and anxiety ${ }^{12}$ reduce aggressive behavioural problems in children with ASD,$^{13}$ and in the long term prevent children with ASD from developing mental health issues. The 'ASD Parent groups' attempt to teach parents ASD-specific strategies so that they feel more confident in managing their child with ASD.

The ASD pathway was required to provide an intervention offer to parents of children and young people with ASD in a system that is under-resourced and struggling to meet the demand. The aim of the QI project was to maximise attendance to the group (using resources more efficiently) and ensure parents left each group more knowledgeable and confident in their ability to manage their child with ASD, as well as being satisfied with the support.

From a service perspective, the regular parent groups have been a helpful way of supporting a large number of parents of children with ASD in the context of limited resources. The monthly groups are providing ongoing support where otherwise parents might require costly individual interventions from CAMHS. This is a useful approach for similar services to consider implementing.

Through the use of QI methodology, we were able to identify barriers to accessing the groups, identify, test and implement change ideas, and highlight effective and efficient systems to increase attendance. We have been able to create an offer that provides specialist provision from a range of professionals with specific expertise in ASD to a large cohort of families. Central to the design and success of the groups has been input from parents (service user feedback) both from the focus group (PDSA 2) and after each group. Feedback suggests the groups are a helpful resource that has enabled parents to access professional knowledge as well as build a social network of other parents who understand their family's needs. Parents report a high level of satisfaction as well as an increase in their knowledge about autism and confidence in managing their child with ASD. Feedback continues to be collected to ensure that the groups remain relevant to parents and effective over time.

The QI approach allowed us to systematically develop efficient systems and cost-effective ways to run interventions within our ASD pathway. It has been a productive way to test, implement and monitor changes, and improve clinical practice.

Acknowledgements We would like to acknowledge the professionals involved in running the groups, particularly Heather Scott, the occupational therapist who cofacilitated the groups. We would also like to thank the service users who attended and gave feedback which formed such an important part of the process.

Contributors The quality improvement project was planned and executed by LAR, a clinical psychologist. She wrote the report and the findings. JRP was involved in the discussions about the study design and edited the reporting of the work. LM supported data analysis and formatted the report and references. LAR is responsible for the accuracy of the overall content.

Funding The authors have not declared a specific grant for this research from any funding agency in the public, commercial or not-for-profit sectors.

Competing interests None declared.

Patient consent for publication Not required.

Provenance and peer review Not commissioned; externally peer reviewed.

Open access This is an open access article distributed in accordance with the Creative Commons Attribution Non Commercial (CC BY-NC 4.0) license, which permits others to distribute, remix, adapt, build upon this work non-commercially, and license their derivative works on different terms, provided the original work is properly cited, appropriate credit is given, any changes made indicated, and the use is non-commercial. See: http://creativecommons.org/licenses/by-nc/4.0/.

\section{REFERENCES}

1. Gordon K, Murin M, Baykaner O, et al. A randomised controlled trial of pegasus, a psychoeducational programme for young people with high-functioning autism spectrum disorder. J Child Psychol Psychiatr 2015;56:468-76.

2. Clubb M. An evaluation of EarlyBird and EarlyBird plus over seven years: the benefits of parents and school staff being trained together. Good Autism Practice 2012;13:69-77.

3. National Autistic Society. The early bird programme, 1997. Available: http://www.autism.org.uk/earlybirdplus [Accessed 25 Sep 2017].

4. National Autistic Society. The early bird plus programme, 2003. Available: http://www.autism.org.uk/earlybirdplus [Accessed $25 \mathrm{Sep}$ 2017].

5. National Institute for Health and Care Excellence. Autism spectrum disorder in under 19s: support and management, Clinical guideline [CG170]. London, 2013.

6. Wistow R, Barnes D. A profile of child and adolescent mental health services in England 2007/8: findings from children's services mapping. Durham University, School of Applied Social Sciences, 2009.

7. National Autistic Society. National autism plan for children (NapC): Plan for the identification, assessment, diagnosis and access to early interventions for pre-school and primary school aged children with autism spectrum disorders (ASD). London, 2003.

8. Simonoff E, Pickles A, Charman T, et al. Psychiatric disorders in children with autism spectrum disorders: prevalence, comorbidity, and associated factors in a population-derived sample. J Am Acad Child Adolesc Psychiatry 2008;47:921-9.

9. Read N, Schofield A. Autism: are mental health services failing children and parents? J Fam Health Care 2010;20:120-4.

10. Howlin P, Rutter M. Treatment of autistic children. Chichester: John Wiley and Sons, 1987.

11. Whittingham K, Sofronoff K, Sheffield J, et al. Stepping stones triple $\mathrm{P}$ : an RCT of a parenting program with parents of a child diagnosed with an autism spectrum disorder. J Abnorm Child Psychol 2009;37:469-80.

12. Prizant BM, Wetherby AM, Rubin E, et al. The SCERTS model: a Transactional, Family-Centered approach to enhancing communication and Socioemotional abilities of children with autism spectrum disorder. Infants and Young Children 2003;16:296-316.

13. Bearss K, Johnson C, Smith T, et al. Effect of parent training vs parent education on behavioral problems in children with autism spectrum disorder. JAMA 2015;313:1524-33.

14. Sofronoff K, Farbotko M. The effectiveness of parent Management training to increase self-efficacy in parents of children with Asperger syndrome. Autism 2002;6:271-86. 